\title{
Studies on the mechanism of non-visualization of diseased human gallbladders during oral cholecystography
}

\author{
M.R. Jacyna, P.E. Ross, D. Hopwood, and I.A.D. Bouchier* \\ Department of Medicine, Ninewells Hospital and Medical School, Dundee DDI 9SY, Scotland, UK.
}

\begin{abstract}
Summary: Oral cholecystography is a well established method for studying the human gallbladder and radiological non-visualization of the gallbladder has been shown to correlate highly with the presence of disease. The exact mechanism by which diseased gallbladders fail to visualize is unclear, but may be due to a failure of the gallbladder to concentrate the luminal contents. Concentration of gallbladder contents is achieved by the reabsorption of water, the driving force for which is active sodium $\left(\mathrm{Na}^{+}\right)$absorption. Therefore $\mathrm{Na}^{+}$transport was studied by measuring the flux of $\mathrm{Na}^{22}$ across isolated human gallbladder mucosa (obtained at cholecystectomy) and compared with the results of oral cholecystography and histological grading.

In 27 gallbladders studied, $59 \%$ absorbed $\mathrm{Na}^{+}$, whilst the remainder secreted $\mathrm{Na}^{+}$. Comparison with histological grading showed that as gallbladders became more diseased they absorbed less $\mathbf{N a}^{+}$ and were more likely to secrete $\mathrm{Na}^{+}$. In addition, gallbladders that absorbed $\mathrm{Na}^{+}$were significantly more likely to visualize on cholecystography than those that secreted $\mathrm{Na}^{+}$. These results indicate that some diseased human gallbladders secrete, rather than absorb, $\mathrm{Na}^{+}$and suggest that the mechanism for radiological non-visualization is failure of fluid absorption and the development of active fluid secretion.
\end{abstract}

\section{Introduction}

Oral cholecystography is a simple and effective method for studying gallbladder function and disease. The technique relies on the ability of the gallbladder mucosa to concentrate adequately the luminal bile containing orally-administered contrast media. Concentration of the bile is achieved by the absorption of water, and successful concentration of this medium results in radiological opacification of the gallbladder. Failure of the gallbladder to visualize has previously been shown to be a very good indicator of underlying gallbladder disease. ${ }^{1}$ Although the majority of diseased gallbladders fail to opacify because of a stone blocking the cystic duct, some have a patent cystic duct and the reason why these gallbladders fail to opacify is unclear. Although it would seem likely to be due to an inability of the inflamed gallbladder mucosa to concentrate adequately the contrast medium, previous work has suggested that it may be due to abnormal absorption of the contrast medium by the

Correspondence: M.R. Jacyna, M.D., M.R.C.P., Department of Medicine, St Mary's Hospital Medical School, Praed Street, Paddington, London W2, UK.

*Present address: Department of Medicine, Edinburgh Royal Infirmary, Edinburgh, Scotland, UK.

Accepted: 11 August 1988 diseased gallbladder mucosa. ${ }^{2}$ Studies on fluid absorption in the human gallbladder, however, are difficult to perform and prone to inaccuracy. As the driving force for water absorption in the gallbladder is sodium ion $\left(\mathrm{Na}^{+}\right)$transport via the mucosal enzyme sodium, potassium-dependent adenosine triphosphatase, ${ }^{3}$ we studied this process in diseased human gallbladders obtained at cholecystectomy using a sensitive radio-isotopic technique. By comparing the findings with the results of oral cholecystography and histology we hoped to gain more information about the mechanism of radiological non-visualization of diseased gallbladders.

\section{Methods}

Human gallbladders

Twenty-seven chronically inflamed human gallbladders, obtained at cholecystectomy from patients with cholelithiasis, were studied. The gallbladders were received within 15 minutes of ligation of the cystic artery and immediately placed in oxygenated saline $(\mathrm{NaCl}$ solution $150 \mathrm{mmol} / \mathrm{l})$ at $4^{\circ} \mathrm{C}$. Portions of the fundus of the gallbladder were gently washed

(C) The Fellowship of Postgraduate Medicine, 1988 
with saline to remove surface bile, and the serosal tissue was removed by blunt dissection and the isolated mucosa mounted in the flux chamber. The remainder of the gallbladder was kept for histological assessment. The degree of chronic cholecystitis was assessed by one observer (DH), who was unaware of the results of sodium transport and radiology. The gallbladders were graded as mildly (grade 1), moderately (grade 2) or severely (grade 3 ) diseased based on the appearance of the epithelial cells, the muscle layer thickness, the size and site of Rokitansky-Aschoff sinuses and the amount of chronic inflammatory cell infiltrate. ${ }^{4}$

\section{Oral cholecystography}

Oral cholecystograms were performed up to 4 months prior to cholecystectomy. On the evening before the examination, the patient ate a light supper consisting of non-fatty foods and then swallowed six $500 \mathrm{mg}$ tablets of lopanoic acid ('Telepaque'; Sterling Research Laboratories) with water. They were then fasted until the examination which took place the following morning.

\section{Sodium transport}

Sodium transport was studied using a modified 'Ussing' flux apparatus, ${ }^{5}$ and the technique used is as previously described with slight modifications. ${ }^{6,7}$ The flux apparatus consists of two perspex hemi-chambers with a section of gallbladder musosa interposed, allowing $0.2 \mathrm{~cm}^{2}$ of both surfaces of the mucosa to be independently bathed. Experiments were performed under 'open circuit' conditions. The medium bathing both surfaces consisted of Krebs bicarbonate buffer ( $\mathrm{pH}$ 7.4) containing glucose $(28 \mathrm{mmol} / \mathrm{l})$, and a tracer dose of $\mathrm{Na}^{22}$ was added to one side of the tissue. The solutions were gassed continuously with $95 \% / 5 \% \quad \mathrm{O}_{2} / \mathrm{CO}_{2}$ and thermostatically maintained at $37^{\circ} \mathrm{C}$. Experiments used four chambers per gallbladder; two for the determination of unidirectional mucosal to serosal flux and two for the determination of unidirectional serosal to mucosal flux. Samples were taken at 10 minute intervals over the 20 to 60 minute period (when a steady rate of $\mathrm{Na}^{22}$ transfer was obtained) from the fluid which initially contained no isotope and the unidirectional flux was calculated as the average of 8 readings (i.e. 4 per chamber). The difference between the two unidirectional fluxes represents the net sodium flux. A net mucosal to serosal sodium flux (sodium absorption) was designated as positive and a net serosal to mucosal sodium flux (sodium secretion) was designated as negative. Data is presented for the experiments as the mean \pm s.e.m. and statistical analysis was performed using Student's $t$-test.

\section{Results}

\section{Sodium transport and histological grading}

Figure 1 shows the net sodium flux of each gallbladder compared to its histological grading. As the severity of cholecystitis increased, the net flux for the gallbladders became less positive (indicating reduced $\mathrm{Na}^{+}$absorption). In the moderately and severely diseased groups, a large proportion of the gallbladders had a net negative $\mathrm{Na}^{+}$flux indicating active secretion of $\mathrm{Na}^{+}$.

\section{Sodium flux and radiological visualization}

Net sodium flux was compared to the results of oral cholecystography. Figure 2 shows that the group of gallbladders that opacified had a net positive (absorptive) $\mathrm{Na}^{+}$flux that was significantly higher than the gallbladders that did not opacify, which had a net negative (secretory) $\mathrm{Na}^{+}$flux.

\section{Discussion}

The main function of the gallbladder is storage of bile during inter-digestive periods, and concentration of the stored bile. ${ }^{8}$ Concentration of the bile occurs by the absorption of fluid and gallbladder mucosa has one of the highest reported rates of

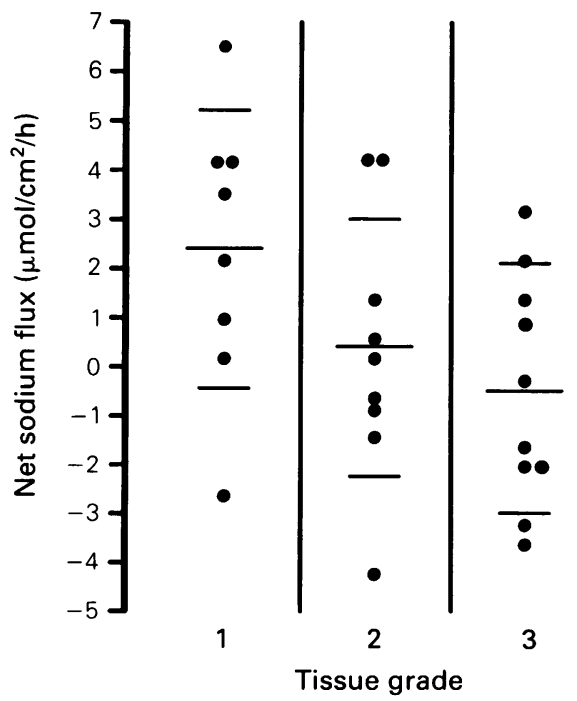

Figure 1 Net sodium flux of gallbladders compared to the histological grade: 1 , mildly diseased; 2 , moderately diseased; 3 , severely diseased. Lines represent the mean and s.e.m. of each group. 


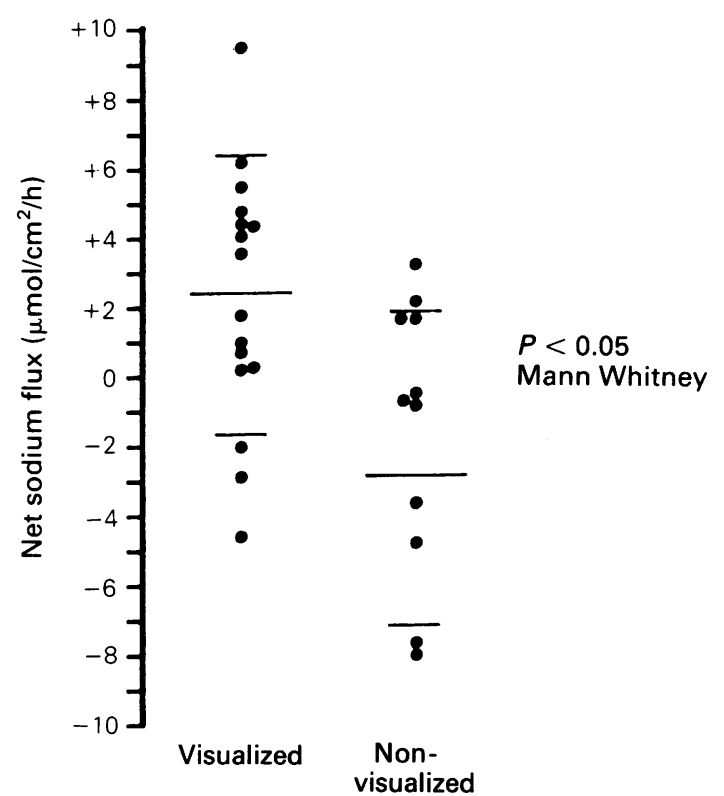

Figure 2 Net sodium flux compared to the results of oral cholecystography performed within the previous 4 months. Lines represent the mean and s.e.m. of each group.

fluid absorption. ${ }^{9}$ The driving force for this absorption is sodium transport via sodium, potassiumdependent adenosine triphosphatase, which actively extrudes $\mathrm{Na}^{+}$across the basolateral cell membrane, creating an electrochemical gradient along which water and anions (bicarbonate and chloride) pass. ${ }^{3}$ Studies have confirmed that the rate of fluid transport correlates directly with sodium, potassiumdependent adenosine triphosphatase activity. ${ }^{10}$

Our results indicate that increasing disease of gallbladders not only reduces $\mathrm{Na}^{+}$absorption (and hence concentrating ability) but also initiates a secretion of sodium by the mucosa. As $\mathrm{Na}^{+}$and water absorption are so intimately linked, it is likely therefore that the reason these gallbladders

\section{References}

1. Baker, H.L. \& Hodgson, J.R. Further studies on the accuracy of oral cholecystography. Radiology 1960, 74: $239-245$.

2. Berk, R.M. \& Wheeler, H.O. The role of water reabsorption by the gallbladder in the mechanism of non-visualisation at cholecystography. Radiology 1972, 103: $37-40$.

3. Wood, J.R. \& Svanvik, J. Gallbladder water and electrolyte transport and its regulation. Gut 1983, 24: 579-593. fail to opacify on cholecystography is because of active fluid secretion into the gallbladder lumen. The effect of this secretion will be a 'washing out' of the gallbladder contents, which will also prevent any contrast medium from entering the gallbladder.

$\mathrm{Na}^{+}$and water secretion in inflamed animal gallbladders is well described and is an energyrequiring process which can take place against an osmotic gradient. ${ }^{11}$ In cholecystitis, fluid secretion is believed to be mediated via prostaglandins, ${ }^{3,11}$ and reversal to the more usual absorption by prostaglandin inhibitors has been demonstrated in both animals ${ }^{12}$ and man. ${ }^{13}$

This is the first study to compare $\mathrm{Na}^{+}$transport in human gallbladders with radiological function. However, Nahrwold et al. ${ }^{14}$ have compared 'shortcircuit current' (which is an indirect measure of $\mathrm{Na}^{+}$transport) of 26 isolated gallbladders with the results of oral cholecystography and found a similar correlation, although there was considerable overlap. Conversely, another study of water transport in the human gallbladder found no correlation between gross fluid absorption and radiological function and the authors postulated that the reason for non-visualization may be due to absorption of the contrast media by the inflamed gallbladder mucosa. $^{2}$ The authors of this latter paper however are self-critical of their method and admit that 'experimental error' may limit the conclusions. Measurement of $\mathrm{Na}^{+}$flux across epithelia is simple and sensitive and our data support the opposite contention that cholecystography does in fact assess the concentrating ability of the gallbladder. We believe that the reason that diseased gallbladders fail to opacify during cholecystography is not only due to failure of fluid absorption but also because of active fluid secretion.

\section{Acknowledgements}

We are grateful to the surgeons at Ninewells Hospital, Dundee for supplying cholecystectomy specimens.

4. Symmers, W.S.-C. In: Systemic Pathology, Vol. 3, 2nd edition. Churchill Livingstone, Edinburgh, 1978, pp 1304-1330.

5. Ussing, H.H. \& Zerahn, K. Active transport of sodium as the source of electric current in the shortcircuited isolated frog skin. Acta Physiol Scand 1951, 23: 110-121.

6. Robinson, J.W.L., Rausis, C., Basset, P. \& Mirkovitch, V. Functional and morphological response of the dog colon to ischaemia. Gut 1972, 13: 775-783. 
7. Grady, G.F., Duhamel, R.C. \& Moore, E.W. Active sodium transport by human colon in vitro. Gastroenterology 1970, 59: 583-588.

8. Rose, R.C. Absorptive functions of the gallbladder. In: Johnson, L.R. (ed) Physiology of the Gastrointestinal Tract. Raven Press, New York, 1981, pp 1021-1033.

9. Diamond, J.M. Transport mechanisms in the gallbladder. In: Code, C.F. (ed) Handbook of Physiology, 6. Alimentary Canal $V$. Williams and Wilkins, Baltimore, 1968, pp 2451-2482.

10. Van Os, C.H. \& Slegers, J.F.G. Correlation between $\mathrm{Na}-\mathrm{K}-\mathrm{ATPase}$ activities and the rate of isotonic fluid transport of gallbladder epithelium. Biochem Biophys Acta 1971, 241: 89-96.

11. Heintze, K., Gotz, R., Koerlings, H. \& Wood, J.R. Characterisation of the prostaglandin induced secretion in the isolated gallbladder of guinea-pig. Naunyn Schmiedebergs Arch Pharmacol 1976, 293 (suppl.): R34.
12. Svanvik, J., Thornell, E. \& Zettergren, L. Gallbladder functions in experimental cholecystitis: Reversal of the inflammatory net fluid secretion into the gallbladder by indomethacin. Surgery 1981, 89: 500-506.

13. Jacyna, M.R., Ross, P.E., Hopwood, D. \& Bouchier, I.A.D. Sodium transport in the human gallbladder and the effects of indomethacin. Clin Sci 1988, 75: 147-149.

14. Nahrwold, D.L., Rose, R.C. \& Ward, S.P. Abnormalities in gallbladder morphology and function in patients with cholelithiasis. Ann Surg 1976, 184: $415-421$. 